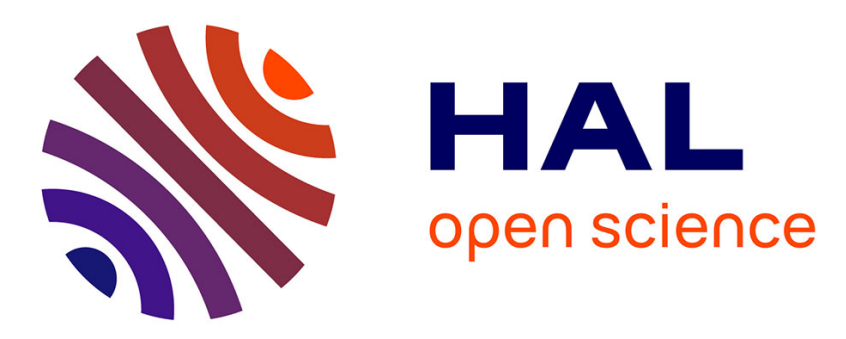

\title{
(DET2009) Framework for Extended Digital Manufacturing Systems
}

Hasse Nylund, Paul H Andersson

\section{To cite this version:}

Hasse Nylund, Paul H Andersson. (DET2009) Framework for Extended Digital Manufacturing Systems. International Journal of Computer Integrated Manufacturing, 2011, pp.1. 10.1080/0951192X.2010.542179 . hal-00664564

\section{HAL Id: hal-00664564 https://hal.science/hal-00664564}

Submitted on 31 Jan 2012

HAL is a multi-disciplinary open access archive for the deposit and dissemination of scientific research documents, whether they are published or not. The documents may come from teaching and research institutions in France or abroad, or from public or private research centers.
L'archive ouverte pluridisciplinaire $\mathbf{H A L}$, est destinée au dépôt et à la diffusion de documents scientifiques de niveau recherche, publiés ou non, émanant des établissements d'enseignement et de recherche français ou étrangers, des laboratoires publics ou privés. 


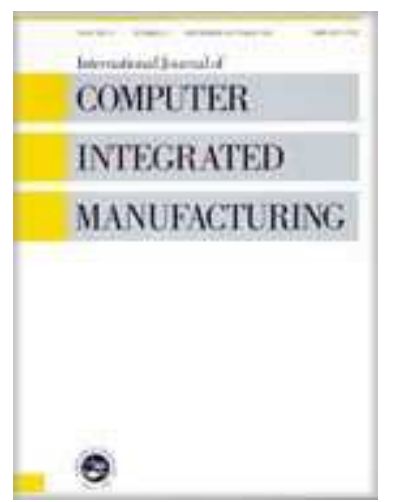

\section{(DET2009) Framework for Extended Digital Manufacturing Systems}

\begin{tabular}{|c|c|}
\hline Journal: & International Journal of Computer Integrated Manufacturing \\
\hline Manuscript ID: & TCIM-2010-IJCIM-0036.R1 \\
\hline Manuscript Type: & Special Issue Paper \\
\hline $\begin{array}{r}\text { Date Submitted by the } \\
\text { Author: }\end{array}$ & 15-Sep-2010 \\
\hline Complete List of Authors: & $\begin{array}{l}\text { Nylund, Hasse; Tampere University of Technology, Department of } \\
\text { Production Engineering } \\
\text { Andersson, Paul; Tampere University of Technology, Department of } \\
\text { Production Engineering }\end{array}$ \\
\hline Keywords: & MODELLING, SIMULATION, INTEGRATION \\
\hline Keywords (user): & \\
\hline
\end{tabular}

\section{SCHOLARONE ${ }^{\text {M }}$ \\ Manuscripts}




\section{Framework for Extended Digital Manufacturing Systems}

Hasse Nylund*

Department of Production Engineering, Tampere University of Technology Korkeakoulunkatu 6

P.O.Box 589, FI-33101, Tampere, Finland

hasse.nylund@tut.fi

tel: +358505746050

fax: +358331152753

Prof. Paul H Andersson

Department of Production Engineering, Tampere University of Technology Korkeakoulunkatu 6

P.O.Box 589, FI-33101, Tampere, Finland

paul.andersson@tut.fi

tel: +358405567872

fax: +358331152753

*Corresponding author 
In this paper a framework for Extended Digital Manufacturing Systems (EDMS) is presented. It aims at an integrated environment for products, production systems, and business processes. The reference model of EDMS consists of manufacturing entities with different roles and similar structures. The main areas of EDMS are modelling, simulation, analysis, and change management. The integrated activities of EDMS are discussed from the viewpoints of augmented intelligence and integrated collaboration activities. The theoretical application areas of the past, present, and future and the process from ideas to innovative solutions are presented. A real-life example of an intelligent manufacturing environment in which several aspects of the EDMS framework are utilised is introduced.

Keywords: modelling, simulation, analysis, integration

\section{Introduction}

Conventional manufacturing has been changing towards more integrated and complex manufacturing networks operating across multiple companies and regions. The changes have been influenced by, for example, globally distributed markets, the opportunities created by Information and Communications Technology (ICT), and the specialisation of manufacturing enterprises in their core knowledge and competences. A framework for extended digital manufacturing systems (EDMS) is introduced that contributes to the challenges manufacturing companies are facing.

The EDMS framework is a part of the concept of Distributed Manufacturing Systems (DiMS) developed in the scientific research project FMS 2010. The DiMS approach aims at collaborative and autonomous manufacturing systems, integrating the activities of products, production systems, and business processes. The EDMS topics presented in this paper are as follows.

- A reference model explaining a manufacturing system with entities, domains, and activities.

- Discussing the main areas of EDMS, which are: modelling, simulation, analysis, and change management.

- Integrated collaboration activities facilitated by augmented intelligence.

- Theoretical application areas making use of the EDMS principles.

- An intelligent academic research environment utilising the EDMS topics discussed.

\section{EDMS Reference Model}


The structure of the reference model of EDMS is based on the principles of holons and Holonic Manufacturing Systems (HMS). The term holon derives from the Greek word 'holos', meaning a whole, and the suffix '-on', meaning a part (Koestler 1989). HMS describes a manufacturing system in terms of autonomous and cooperative manufacturing entities, or holons (Valckenaers et al. 1994). This autonomy means that the entities can perform their own tasks independently without the help of other entities, whilst the cooperation means that the entities can collaborate with each other to fulfil their individual areas of responsibility and to reach the objectives they share with other manufacturing entities.

\subsection{Structure of a System}

The reference structure of EDMS consists of manufacturing entities and their related domains and activities. An entity, being autonomous, is something that has a distinct existence and can be differentiated from other entities. The term 'entity' has similarities to other terms, such as object, module, agent, actor, and unit. A domain is an expert area in which two or more entities are collaborating. Domains have certain roles in the system and their own responsibilities and specific objectives. An activity is a set of actions that accomplish a task that is related to the entities and domains, as well as to their context.

The structure of EDMS is presented in Figure 1. It is a basic presentation of the manufacturing entities, their related domains, and overall views of the different areas of responsibilities. The entities - products, resources, and orders - are loosely based on the HMS reference architecture Product-Resource-Order-Staff Architecture (PROSA) (Van Brussel et al. 1998, Wyns 1999).

Figure 1 
- Products represent what the manufacturing system offers to its customers. The characteristics of the products specify the requirements for the manufacturing system, i.e. what the system should be able to do.

- Resources embody what is available to manufacture the products. The characteristics of the resources determine what kinds of characteristics of the products can be manufactured.

- Orders represent instances of products that are ordered by customers. They define the volume and variation requirements of the products ordered, as well as the capacity and scalability requirements for the manufacturing system.

The EDMS approach includes process, production, and business domains among the manufacturing entities. The descriptions of the manufacturing domains are, briefly, as follows.

- The process domain describes the individual manufacturing capabilities. It is responsible for ensuring that a system has all the capabilities it needs, i.e. that for each product feature there exists at least one resource that has the method needed to realise the feature.

- The production domain is responsible for the capacity and scalability of a manufacturing system. The challenge is to respond to the fluctuation of customer orders, realised as changing volume and variation in the capabilities needed, ensuring that there is the right amount of resources with the methods that are needed to deliver the orders at the right time.

- The business domain is responsible for the markets, i.e. that the products offered correspond to what the customers are demanding. The decisions in the business domain affect both the capabilities that are needed and the required capacity and scalability.

The approach has similarities to next-generation Total Quality Management (TQM-

S), and to its three core techniques: TMS (Toyota Marketing System), TDS (Toyota

Development System), and TPS (Toyota Production System); see Amasaka (2004).

The competence is the focal point of a manufacturing system. The activities in the content and context of the entities and domains have to be constantly developed and managed, i.e. the manufacturing system has to be responsive and adaptive to all changes. 


\subsection{Structure of Entities}

Internally, manufacturing entities consist of digital, virtual, and real existences representing their autonomy, and a communication part as the enabler of collaboration with other manufacturing entities. The internal structure of the manufacturing entities is presented in Figure 2. The descriptions of the internal parts of the manufacturing entities are:

- The real part represents the physical entities that exist in the manufacturing system, such as machine tools, robots, and conveyors.

- The virtual part is a presentation of the physical entity, usually as a computer model.

- The digital part is the information and knowledge of the real and virtual parts. It is a description of the properties of the entities.

- The communication part is responsible for the collaboration capabilities, both the language and content of the messages communicated between the entities existing in the manufacturing system.

Figure 2

A manufacturing entity may not have all the parts all the time and the combination of the parts usually changes during their lifecycles, as well as in the research and development phases from ideas to innovative solutions. In a broad sense, all the data that exist in computer systems are digital. One way to differentiate the digital and virtual parts in EDMS is that the digital is something that, when printed, will not lose the information, whilst the behaviour and properties of the virtual part will not exist when printed.

In EDMS the digital part of an individual manufacturing entity usually needs to be gathered from several different sources. Portions of the digital part can exist in, for example, information-rich simulation models (the virtual part), as well as local and global information storage systems. Despite the division of the digital part, it should be accessible to all related parties who have the right to access it and could benefit from it, regardless of their time or location. 


\subsubsection{Fractal self-similarity}

A fractal is an independently acting manufacturing entity that can be precisely described (Warnecke 1993). The FrMS approach explains the self-similarity of the manufacturing entities at different structuring levels, as well as their dynamic characteristics.

In EDMS, a manufacturing system consists of sub-systems that are generally similar to each other, and to the manufacturing system itself. At the same time a manufacturing system is a sub-system of a greater system. The hierarchy of resource entities in an industrial environment can be presented as a taxonomy, as structuring levels of industrial ecosystems, enterprise networks, enterprises, factories, manufacturing systems, and manufacturing stages, as well as manufacturing units and devices (Nylund et al. 2009a). Similarly, the hierarchy of product and order entities forms its own taxonomies. A product entity includes levels of, for example, portfolio, product families, products, modules, components, and parts. An order entity, which, at the highest level, is a customer order, can be divided into several order instances down to individual blank parts to be transformed into finished parts in a manufacturing unit.

A level above includes all the levels below. As the entities on all levels are autonomous entities, the complexity at a certain level only includes the intelligence of the cooperation of the entities on a lower level. This reduces the complexity of the manufacturing activities. The formality of the complexity increases from top to bottom, while the role of humans becomes more important from the bottom up. The role of humans changes considerably on the level of the enterprise network, where the negotiations between different enterprises become the most important factor. 


\subsubsection{Human component}

The intention of EDMS is not to replace humans with machines and information systems. People have different roles in an efficiently operating EDMS, from simple tasks to complex decision-making processes.

The digital and human components combine to make up the total knowledge of the system, as the knowledge can be explained with explicit and tacit components (Nonaka and Takeuchi 1995). The explicit part of the knowledge can be described precisely in a formal way, and can be included as the digital knowledge of an EDMS. The skills of humans are explained as the tacit dimension of knowledge which, presented digitally, may lead to unclear situations and can be wrongly understood.

\section{Extended Digital Manufacturing Systems}

The research on digital manufacturing systems, factories, and enterprises has no commonly used definitions. Typical issues mentioned are, for example: the collection of systems and methods (Maropoulos 2003); the integration of current engineering practice and technology (Reiter 2003); the mapping of all the important elements of the enterprise processes (Monostori et al. 2002); an integrated approach to enhance the product and production engineering processes (Kühn 2006), and the entirety of all methods and tools (Hellmann et al. 2003). The aim of managing the typically isolated and separate activities as a whole by means of Information and Communications Technology (ICT) is similar to the definitions.

\subsection{Definition of EDMS}

A digitally presented manufacturing system contains the information and knowledge of manufacturing entities and activities that it is reasonable to represent in a digital form. This, at its best, makes possible efficient collaboration between all the manufacturing activities and related parties. An EDMS can briefly be defined as follows: "an integrated and collaborative environment for humans, machines, and 
information systems to act and interact to enhance the research, development and management activities of products, production systems, and business processes, supporting knowledge-intensive decision making in the entirety of their lifecycles." The key characteristics of the DiMS concept, which are mostly related to EDMS, can be explained as follows:

- an adaptive and knowledge-based manufacturing system consisting of autonomous and co-operative manufacturing entities;

- service-oriented and context-aware manufacturing activities, where the communication between the entities is seen as services and the skills and knowledge are kept as the autonomy of the entities;

- formally presented information and knowledge presented as a digital manufacturing system, a domain where collaboration activities are happening between humans, machines, and information systems.

\subsection{The main areas of EDMS}

The main areas of EDMS are modelling, simulation, and analysis, as well as the management of changing information and knowledge. The enablers for these are the possibilities provided by ICT tools and principles that enable the areas to be connected via the digital parts of the manufacturing entities, together with human knowledge and skills.

\subsubsection{Modelling and Simulation}

The role of modelling is the aim of creating a virtual replica of a real-life manufacturing entity. It is used to understand a system and its characteristics and behaviour. It can be used to repeat or refine an activity to achieve a specific result, as well as to extract a system in order to apply it to a different content or context (Dilts 2005). Simulation aims to understand the dynamic behaviour of the collaborating manufacturing entities and how the characteristics and behaviour of a system change over time.

In EDMS the modelling and simulation activities can be focused on the study of manufacturing capabilities and capacity (Nylund et al. 2009a). These can be 
divided into process and production domains, as presented in Figure 1. The capabilities, as individual manufacturing activities, belong to the process domain. The manufacturing process simulation can be focused on individual machine tools and devices, as well as designing and developing manufacturing cells or stages, the subsystems of a manufacturing system. The capacity is mostly concerned with the production domain dealing with customer orders. The main concern is the efficiency of the flow of manufacturing material and information.

The simulation areas of manufacturing processes and flow have a different viewpoint to the business domain. With the simulation of the manufacturing process the ability to manufacture all products can be ensured. It is related to what is offered to customers and it does not concern what and how much the customers are actually ordering. In the manufacturing flow simulation it is assumed that all the products offered can be manufactured. The focus is on that the volume and variation of customer orders that is needed can be manufactured and delivered at the right time.

The simulation models are the virtual parts of the manufacturing entities that often also include pieces of the digital part of the entities. As the entities are described as belonging to different fractal levels, different kinds of simulation tools are applied on different fractal levels. On the fractal levels of enterprise networks, enterprises, factories, and manufacturing systems the concern is typically about the flow of material and information and therefore these levels can be simulated using discrete event simulation (DES). The level of detail that is required to construct a simulation model depends on what is planned to be acquired from the simulation model. With a rough-level simulation the focus can be on the basic principles and structures of systems, e.g. layout planning, while in a simulation on a more detailed level the goals relate to the controlling, planning, and scheduling of the manufacturing activities. 
Inside a manufacturing system different kinds of modelling and simulation are applied. The level of the manufacturing stage represents physical or logical areas, where example areas of modelling and simulation are the simulation of a manufacturing cell for the designing of the cell layout and material handling and holding, as well as ergonomic simulations relating to the tasks and safety of the humans performing manual work. Manufacturing units represent the fractal level of individual machine tools and devices. Areas of modelling and simulation are, for example, computer-aided design (CAD) and computer-aided manufacturing (CAM), e.g. offline programming of machine tools and robots.

\subsubsection{Analysis}

The analysis aims to verify and validate the results of simulations. The consequences of the solutions can be evaluated and the results of solution alternatives can be compared. Typical areas for analysis are, for example:

- monitoring the state, characteristics, and behaviour of the system, as well as how they change over time;

- comparing alternative solutions, e.g. different system configurations and control principles;

- comparing the performance of different systems to aid in selecting the best suitable alternative.

\subsubsection{Change Management}

Manufacturing systems operate in a constantly changing environment. The changes can be external or internal, direct or indirect, mandatory or voluntary. Change management aims to keep a manufacturing system operating efficiently and growing as it evolves over time. Changes in one area should be announced to the whole system. The earlier the changes and their impacts are known, the better the chance is of an efficient solution being implemented. For example, changes in product requirements caused by a future product in the development phase may require new 
capabilities and the planning for the new resources can be started. In a similar fashion, a new resource to be included into the existing system can offer new capabilities and these can be utilised in the development of the product even before the resource is actually implemented into the real system.

Change management can roughly be divided into managing the distributed information and knowledge that originates from different sources and managing the communications between manufacturing entities of different levels of intelligence (Nylund et al. 2009b). The evolution of the system entities can be seen from two different aspects of changeability (Nylund et al. 2008b):

- changing by requirements - the ability to change to meet new requirements, where the structure of the system is changed, and

- changing by learning - the ability to improve the current capabilities by learning and updating the information and knowledge.

Typically, the entities must change during their existence both to meet the new requirements and to improve their activities (Nylund et al. 2009a).

\section{Integrated Activities}

The digital part of the manufacturing entities is the only part that can be efficiently used to integrate the entities that exist in a physically distributed form. This requires the entities to be able to communicate via information systems. An EDMS has basically four types of entities when it comes to their communication capabilities, i.e. human entities, entities with cognitive intelligence, entities with machine intelligence, and passive entities (Salminen et al. 2008). Humans are the most versatile entities and they can perform different kinds of tasks, from the simple updating of parameters to complex negotiation processes. Entities with cognitive capabilities mimic human behaviour, i.e. they have capabilities, such as perception, reasoning, learning, and planning (Zäh et al. 2007). Entities with machine intelligence, such as machine tools 
and robots, can control themselves. They can be closed systems that do not communicate with other entities, or open if they can send and receive messages and act on the basis of the content of the messages. Passive entities, such as simple work pieces and old machinery, do not have intelligence and therefore cannot communicate by themselves in the system they exist in.

\subsection{Augmented Intelligence}

In an ideal EDMS all the manufacturing entities are intelligent, both in their autonomy and communication capabilities. Intelligent autonomy means that the entity has a digital representation of its own capabilities, which is updatable over time. Intelligent collaboration indicates that the entity can communicate its own state and negotiate in the system to achieve mutual goals with other entities. Figure 3 illustrates the idea of augmenting the intelligence of the different types of entities.

Figure 3

Communication in a digital manufacturing system varies according to the communication intelligence of the entities involved. Humans communicate via user interfaces, such as the graphical user interfaces (GUI) of software applications and control panels of machine tools. Entities with cognitive intelligence mimic human behaviour in their collaboration and they have built-in communication capabilities. Entities with machine intelligence either need to be connected to a digital system or the communication capabilities need to be built in order for them to communicate in the digital system. Passive entities may only include data and information, which can be made updatable using, for example, radio-frequency identification (RFID) tags incorporated into the entities. As passive entities have no communication capabilities themselves, the intelligence is built into the digital manufacturing system, enabling passive entities to be part of the collaboration activities. Entities on all intelligence 
levels may lack the ability to communicate some necessary data and information, which can be achieved by integrating, for example, sensors, actuators, readers, or machine vision into the entity. Intelligent entities have their autonomy and they only send the parameters that are needed to the EDMS, keeping the intelligence as their own property. Passive entities have only the parameters they need stored by themselves and the intelligence is built up in the digital part of the EDMS.

The above discusses augmenting the intelligence of real parts of the manufacturing entities existing physically in a system (see Figure 2). To be able to create the virtual part, the simulation model, it has to be able to mimic the communication capabilities added to the real part. This rules out any software that does not have the required functions built in or does not incorporate the possibility of creating the additional functionality in the simulation model.

\subsection{Integrated Collaboration}

The collaboration is loosely based on the principles of SOA, explaining the manufacturing entities as service requesters and providers, and a service broker representing the intelligence on an upper level of the hierarchy. The main idea is that the manufacturing activities are presented as services. Therefore, as a service is an activity between two or more manufacturing entities, the services can be classified horizontally into different domains, as presented in Figure 1. Vertically, a service that exists on an upper fractal level is divided into several services on a lower level.

The communication can be anything from exchanging parameters to negotiation processes, and the level of intelligence has to be higher when the complexity of the collaboration increases. Communication can also exist between different internal parts of the entities. For example, a product design consisting of digital information and a virtual model may communicate with real manufacturing 
resources with the aim of finding efficient processes to manufacture the product in the future. Implementing the augmented intelligence in the manufacturing entities means, for example, that:

- they can introduce their capabilities and requirements when they enter the system, and announce when they leave the system;

- a resource entity can notify the system of changes in its capabilities, and a product entity can notify the system of its changed requirements;

- a product entity can query its service requests to find possible existing providers, and

- an entity can announce its current state and known future activities. For a resource entity the activities can be the jobs in a queue, and, for a product entity, the services it will require.

\section{Theoretical Application areas}

\subsection{Past, Present, Future}

EDMS can be utilised in the past, present, and future time dimensions. The past represents what has happened. It is the digital memory of the system. The time dimension of the present, what is happening now, is used to operate the current system by monitoring the state of the system and comparing it to the desired state. The future dimension makes it possible to plan future manufacturing activities ahead and to compare different changes in strategies.

Figure 4

The past exists as the history data and information collected from the manufacturing activities when they happened. It is used to analyse previous activities in order to find out what happened and the reasons why it happened. In finding the root causes for phenomena, the system can learn from its past and prevent unwanted situations in the future. Rules for the autonomy of the manufacturing entities, as well as for their collaboration, can be enhanced and new rules can be created.

The present here means the near future, where no major changes are planned. It is, for example, the use of existing resources and the planning and scheduling of 
customer orders that have already been placed. In the present the digital and real existences co-exist. As the system operates the activities are logged, creating new history data to be analysed and to aid decision making. The state of the real manufacturing system can be seen in the digital manufacturing system and action can be taken with the state of the system as a starting point.

The dimension of the future relies on the information and knowledge gathered from the system previously. Future design and development decisions are syntheses of existing capabilities and requirements combined with future goals and possibilities. The viewpoint of the future can be divided into tactical decisions and visions. Tactical decisions consider the near future into which the manufacturing system is heading. Future visions are similar to tactical decisions, the difference being the time horizon. The outcome of future visions is more obscure but there are more possibilities to be investigated.

The information and knowledge from analysing the past, collecting data from the present, and forecasting the future is stored in the form of receipts. A receipt holds the capabilities of a system, constantly updating and refining the best practices in conjunction with human skills and know-how. The receipts are the basis of the operations in the real present, the only time dimension in the real world.

\subsection{Process from ideas to solutions}

Figure 5 represents a process from ideas and the need for change to innovative solutions on the fractal level of factories or manufacturing systems where DES software is being used. The process consists of a chain of activities where the results evolve towards more precise solutions. Each of the phases has its enablers as inputs and the activity creates results as outputs. The results affect the enablers in the 
following phases of the process. The process is also iterative as it is possible to go back to previous phases in order to change or refine them.

The need for change can arise, for example, from economic, social, environmental, and technological aspects (ESET) that define competitive and sustainable manufacturing (CSM) (Jovane et al. 2009). The changes can also derive from voluntary ideas that are seen to improve the competence of the system. If an EDMS had not been developed in the past, the current system has to be analysed to create the digital information and knowledge. The synthesis of the existing system and possible changes form the new requirements for the future system.

\section{Figure 5}

The combination of feasible new possibilities and existing capabilities forms the solution principles. The results are digital entities and abstract and conceptual descriptions, including the objectives and preliminary properties of the future system. When the descriptions evolve towards a more detailed level, possible technologies can be investigated, resulting in alternative solutions. The solution alternatives can be modelled as virtual entities that include, in addition to their digital description, for example, 3D models with their own operating rules, motion, and behaviour. The virtual entities are dependent on the level of details available as well as the simulation environment that is being used.

Combining the existing and new virtual entities forms a rough simulation model. The solution that is implemented has to be verified to make sure that the behaviour and cooperation of the entities in the simulated system are modelled correctly. The verified simulation model can be used to run test experiments. By analysing the results from the simulation model and comparing them with known or predicted outcomes, the behaviour of the simulation model can be validated. When 
the simulation model is verified and validated, it can be used for manufacturing experiments. The experiments are used to analyse the behaviour of the system, and can lead towards more effective and innovative solutions.

In addition to the analysis of the simulated system, the process from ideas to solutions should also be analysed. The process takes time and increases the engineering costs and, if possible, already existing virtual entities should be used. New created virtual entities should be modelled considering the re-use of the simulation models reducing the time and costs of the future simulation studies.

\section{Intelligent manufacturing environment}

The intelligent manufacturing environment, a robot machining cell, is an academic research environment (see Figure 6), where several of the theoretical ideas of the EDMS are utilised. The initial version of the laboratory demonstration was introduced during the Tampere Manufacturing Summit seminar, which was held in Tampere, Finland, in June 2009. The research environment can be utilised in various activities, which are, for example:

- designing, developing, and testing current and future research topics;

- testing and demonstrating possible solutions for industrial partners in ongoing research projects;

- an educational environment for university students and company personnel to introduce the latest results in the area of intelligent manufacturing.

Figure 6

\subsection{The structure of the environment}

The manufacturing environment follows the EDMS structure presented in Figure 1. It focuses mostly on the manufacturing process domain and the creation of the intelligence of the resource entities. The environment represents a single manufacturing stage, which makes the production domain fairly simple. The product entities are simple cylindrical pieces with either two or four holes. 
Figure 7

Figure 7 represents the taxonomy of the resource entities of the robot machining cell, which is a resource entity at the level of a manufacturing stage. The cell is divided at the manufacturing unit level into a fixture unit, a robot unit, and a human operator. The robot unit consists of a robot, a Safety Eye, and a drilling machine. The robot is a Fanuc F-200iB six-degrees-of-freedom servo-driven parallel link robot. The manufacturing processes are carried out with a Suhner BEX 35 machining unit. The fixture unit is divided into a physical fastening element and a camera unit. In some of the manufacturing activities, such as fastening the work pieces, a human operator is required. The environment described here exists physically in a laboratory environment, as well as virtually, in the form of simulation models built with several different software packages, for example CATIA, DELMIA, and 3DCreate.

\subsubsection{The digital part of the environment}

The EDMS information and knowledge, which is not the autonomy of the demonstration entities, is handled in a Knowledge Base (KB). It holds the augmented intelligence of the manufacturing entities that lack intelligence. The KB, developed in a research project, IP-PISA, is a platform-independent and open integrative solution between different manufacturing entities (Lanz et al. 2008). The KB also includes the digital information and knowledge collected from the manufacturing activities of the demonstration.

\subsection{Communication capabilities of the environment}

The communication activities within the manufacturing environment are used to keep the system running as planned and to gather data to analyse and improve the environment. The robot is aware of its status and can communicate it to the other 
entities in the system. The intelligence of the robot is augmented using force, acceleration, and AE sensors. Data from the sensors are stored in the $\mathrm{KB}$ and are monitored against an acceptable value range. If the data from the sensors reach a predefined limit, the robot will stop its process. The statuses of the robot unit are idle, busy, and waiting for a service that has been requested to be started. The robot waits until a human operator fastens the product that has been ordered.

The fixture itself is a passive entity to which two products can be attached at the same time. Its intelligence is augmented by using a camera device. The combination of the fixture and the camera makes it an intelligent entity that can announce its state to the entities it is collaborating with. The possible states for the fixture unit, for both places independently, are empty, blank or finished part attached, or an error status. During the manufacturing process the status of the fixture unit can be ascertained from the robot unit as its visibility is limited when the robot is in operation.

The safety camera system is used to monitor the working environment of the robot, as well as to control the operation of the robot. The area, approximately 15 metres x 15 metres, can be divided into several separate areas that can have different meanings, for example areas to tell the robot to slow down its movement or perform an emergency stop. When the monitoring system detects movement in one area, the environment will perform a predefined task. In addition to the monitoring of the area, it can be used to control the activities of the environment.

The data gathered from the machining process are processed and stored into the KB. The data are used in the real-time condition monitoring and can also be utilised to compare the measured values of the real system with the theoretical values from the virtual system. In addition, data from every manufactured product and 
operational values during that time are logged into the $\mathrm{KB}$, which makes it possible to trace afterwards when and in what context the part was manufactured, as well as to use the data to analyse the performance of the environment.

\subsection{Development and operational manufacturing activities}

The intelligent manufacturing environment can demonstrate both the development and operational activities of manufacturing systems. The development activities focus on creating new capabilities for the system, whilst in the operational activities the aim is to improve the existing capabilities of the system.

\subsubsection{Manufacturing development}

Figure 8 illustrates the demonstration process at a development level. The manufacturing methods, i.e. the manufacturing capabilities of the resource entities, are described and stored in the KB. Similarly, the product entity, being a CAD model, is examined in order to recognise the product features. For each product feature, a service request is created in order to find a service provider from the KB. If a suitable service exists, the result is that the feature can be manufactured; otherwise, a new service request is created. The new service can now be tested using virtual manufacturing and, if needed, also using real manufacturing. The result is validated and the outcome is either a new capability or a rejected service. If the service can be provided, the new capability is added to the $\mathrm{KB}$. If the result is a rejected service, the current system does not have the capability the product entity requires. In this case it has to be decided whether to try to find an alternative solution from the existing environment or to seek the possibility of reconfiguring the existing system or implementing new capabilities into the system.

Figure 8 


\subsubsection{Manufacturing operation}

On the operational level all the capabilities that are needed exist. This case represents a typical situation in manufacturing companies where a known set of products are manufactured with a known set or resources and their capabilities. In the demonstration environment it is possible to try to enter an unknown order into the system but it will not be accepted. An order for a known product will be added to the end of a queue of orders waiting to be manufactured. The robot cell is, by default, in its idle state until a new order is placed. The fixture may contain one or two blank parts and, when all the blank parts have been manufactured, it announces that all the attached parts have been manufactured and the human operator can detach the finished parts. For the changing of the products from finished to new blanks, the operator moves to a certain area in the environment and the robot unit understands that it needs to go to a certain position and wait until the parts have been changed. After attaching new blanks, the operator gives the robot unit permission to continue. The communication between the operator and the robot unit is made possible using the Safety Eye system.

\subsection{Performance monitoring and measurement}

The measurements of the manufacturing environment can be divided into direct measurements using the sensors and measurement devices and indirect measurements analyzing the logged data stored in the KB. Examples of the direct measurements are:

- process quality assurance, a real-time measurement using force, acceleration, and $\mathrm{AE}$ sensors;

- process stability monitoring following the electrical variations of the robot servomotor caused by the cutting forces;

- energy consumption monitoring using a Carlo Gavazzi EM21 72D energy meter.

The indirect measurements offer performance metrics that can be gathered from the

KB. The indirect measurements have not been implemented yet, but logged data can be analysed and several performance metrics can be obtained. Examples of these are: 
cost-, quality-, and time-related metrics; material and energy consumption, and manufacturing efficiency and reliability-related metrics.

\subsection{Planned future work on the environment}

The future work on the intelligent manufacturing environment includes further developing, testing, and piloting of emerging research questions and ideas. In the near future, the environment will be extended by connecting more machine tools and other units to it, in which case the system will become more complex and will correspond better to a typical manufacturing system. The increased complexity expands the challenges and opportunities of, for example, production control, the factory environment, context-awareness, and communication, which are typical preconditions for an intelligent manufacturing system.

The extension of the system has already been started by adding machine tools (a lathe and a machining centre) and a coordinate measuring machine (CMM). These devices have their own capabilities, i.e. they increase the total capabilities of the environment. Partially, the capabilities of the different devices are the same or similar, which makes it possible to demonstrate the selection of the most feasible service provider in terms of capability and availability during a moment in time and during a longer period of time in correspondence between the goals and objectives. The objectives can be such as the fastest, greenest, or cheapest service provider, yet again this requires very complex reasoning and definition of which role defines the goal. In addition to the physical entities, corresponding virtual computer models will be constructed. Both the real and virtual parts of the entities will be connected to the knowledge base, the digital part, on the basis of the theory of EDMS. 


\section{Benefits and Challenges of EDMS}

EDMS is an efficient environment for problem-solving. Possible mistakes can be corrected, rethought, and redesigned before becoming involved in the real manufacturing system. The experts in a manufacturing enterprise acquire a wider outlook compared to their own special domain of knowledge. The challenge is managing the distributed information and knowledge that originates from different manufacturing sources, and managing the communications between manufacturing entities with different levels of intelligence. The information has to be presented formally in a predefined and standard format, and it has to be accurate and up-to-date so that it can be trusted and used in decision-making activities.

\section{Conclusions}

The framework for EDMS was discussed explaining a system with entities playing different roles, and existing in digital, virtual, and real forms. The manufacturing domains and activities form an integrated platform in the past, present, and future time dimensions, as well as in the process from ideas to innovative solutions. An intelligent academic manufacturing environment was introduced that utilises the theoretical aspects of EDMS.

The research discussed in this paper is co-financed by Tekes, the Finnish Funding Agency for Technology and Innovation, and major companies in Finland. This paper was presented at the DET2009 conference held at the University of Hong Kong during 14-16 December 2009 and included in the conference proceedings published by Springer.

Amasaka, K., 2004. Science SQC, New Quality Control Principle: The Quality Strategy of Toyota. Tokyo: Springer Verlag.

Dilts, R., 2005. Modeling [online]. Robert Dilts NLP Home Page. Available from: http://www.nlpu.com/Articles/artic19.htm [Accessed 30 ${ }^{\text {th }}$ March 2010].

Extreme Programming [online]. http://www.xprogramming.com/ [Accessed $30^{\text {th }}$ March 2010].

Hellmann, A., Jessen, U. and Wenzel, S., 2003. e-Services - a part of the Digital Factory. The 36th CIRP-International Seminar on Manufacturing Systems, 35 June 2003 Saarbrucken, Germany. 199-203.

Jovane, F., Westkämper, E. and Williams, D., 2009. The Manufuture Road: Towards Competitive and Sustainable High-adding-value Manufacturing. Berlin: Springer Verlag. 
Koestler, A., 1989. The GHOST in the MACHINE. Arkana Books.

Kühn, W., 2006. Digital Factory - Integration of simulation enhancing the product and production process towards operative control and optimization. International Journal of Simulation, 7 (7), 27-39.

Lanz, M., Garcia, F., Kallela, T. and Tuokko, R., 2008. Product-Process Ontology for Managing Assembly Specific Knowledge between Product Design and Assembly System Simulation. In: S. Ratchev, and S. Koelemeijer S eds. Micro-assembly technologies and applications. 99-108.

Maropoulos, P.G., 2003. Digital enterprise technology-defining perspectives and research priorities. International Journal of Computer Integrated Manufacturing, 16 (7-8), 467-478.

Monostori, L., Haidegger, G., Váncza, J. and Viharos, Zs.J., 2002. Digital Enterprises: A national project in Hungary. Proceedings of 1st CIRP(UK) International Seminar on Digital Enterprise Technology, September 2002 Durham, UK. 269-272.

Nonaka, I. and Takeuchi, H., 1995. The Knowledge-Creating Company: How Japanese Companies Create the Dynamics of Innovation. Oxford: Oxford University Press.

Nylund, H., Salminen, K. and Andersson, P.H., 2008a. Digital virtual holons - An approach to digital manufacturing systems. In: M. Mitsuishi, K. Ueda and F. Kimura eds. Manufacturing Systems and Technologies for the New Frontier, The 41st CIRP Conference on Manufacturing Systems, 26-28 May Tokyo, Japan. 103-106.

Nylund, H., Salminen, K. and Andersson, P.H., 2008b. A multidimensional approach to digital manufacturing systems. Proceedings of DET2008 - 5th International Conference on Digital Enterprise Technology, 22-24 October Nantes, France. 44-51.

Nylund, H., Salminen, K. and Andersson, P.H., 2009a. An approach to the Integrated Design and Development of Manufacturing Systems. In: R. Roy, and E. Shehab, eds. Proceedings of the $19^{\text {th }}$ CIRP Design conference, Competitive Design, 30-31 March 2009, Cranfield University, UK. 428-435.

Nylund, H., Salminen, K. and Andersson, P.H., 2009b. Digital manufacturing networks - challenges and opportunities. Proceedings of 3rd International Conference on Changeable, Agile, Reconfigurable and Virtual Production (CARV 2009), 5-7 October 2009 Munich, Germany. 995-1004.

Nylund, H. and Andersson, P.H., 2010. Simulation of service-oriented and distributed manufacturing systems. Robot Comput Integr Manuf (2010), doi:10.1016/j.rcim.2010.07.009.

Papazoglou, M.P. and Georgakopoulos, D., 2003. Service Oriented Computing. Communications of the ACM, 46 (10), 25-28.

Pilz [online]. Safety Eye. http://www.pilz.com/ [Accessed 30th March 2010].

Reiter, W.F., 2003. Collaborative engineering in the digital enterprise. International Journal of Computer Integrated Manufacturing, 16 (7-8), 586-589.

Salminen, K., Andersson, P. and Nylund, H., 2008. The emergence process of an adaptable manufacturing system based on an evolution paradigm. Flexible Automation and Intelligent Manufacturing, FAIM2008, 30 June - 2 July Skövde, Sweden. 1011-1018.

Valckenaers, P., Van Brussel, H., Bongaerts, L. and Wyns, J., 1994. Results of the Holonic Control System Benchmark at the KU Leuven. Proceedings of the CIMAT Conference, Troy, NY, USA. 128-133. 
Van Brussel, et al., 1998. Reference architecture for holonic manufacturing systems: PROSA. Computers in Industry, 37, 255-274.

Warnecke, H.J., 1993. The Fractal Company: A Revolution in Corporate Culture. Berlin: Springer-Verlag, Berlin.

Wyns, J., 1999. Architecture for Holonic Manufacturing Systems - The Key to Support Evolution and Reconfiguration. Thesis (PhD). KU Leuven.

Zäh, M.F., et al., 2007. Towards the Cognitive Factory (Keynote Paper). Proceeding of the 2nd International Conference on Changeable, Agile, Reconfigurable and Virtual Production, 22-24 July Toronto, Ontario, Canada. 2-16. 
Figure 1. Basic structure of the EDMS entities and their related domains Figure 2. Internal structure of a manufacturing entity (Nylund et al. 2008a)

Figure 3. Adding augmented intelligence and levelling the differences in intelligence levels

Figure 4. Digitally co-existing past, present, and future time dimensions Figure 5. The process from ideas to innovative solutions using factory simulation, adapted from Nylund and Andersson (2010)

Figure 6. Real and virtual views of the robot cell environment

Figure 7. Taxonomy of the resource entities of the robot machining cell

Figure 8. An illustration of the demonstration process during the manufacturing development phase 
No tables in the manuscript 


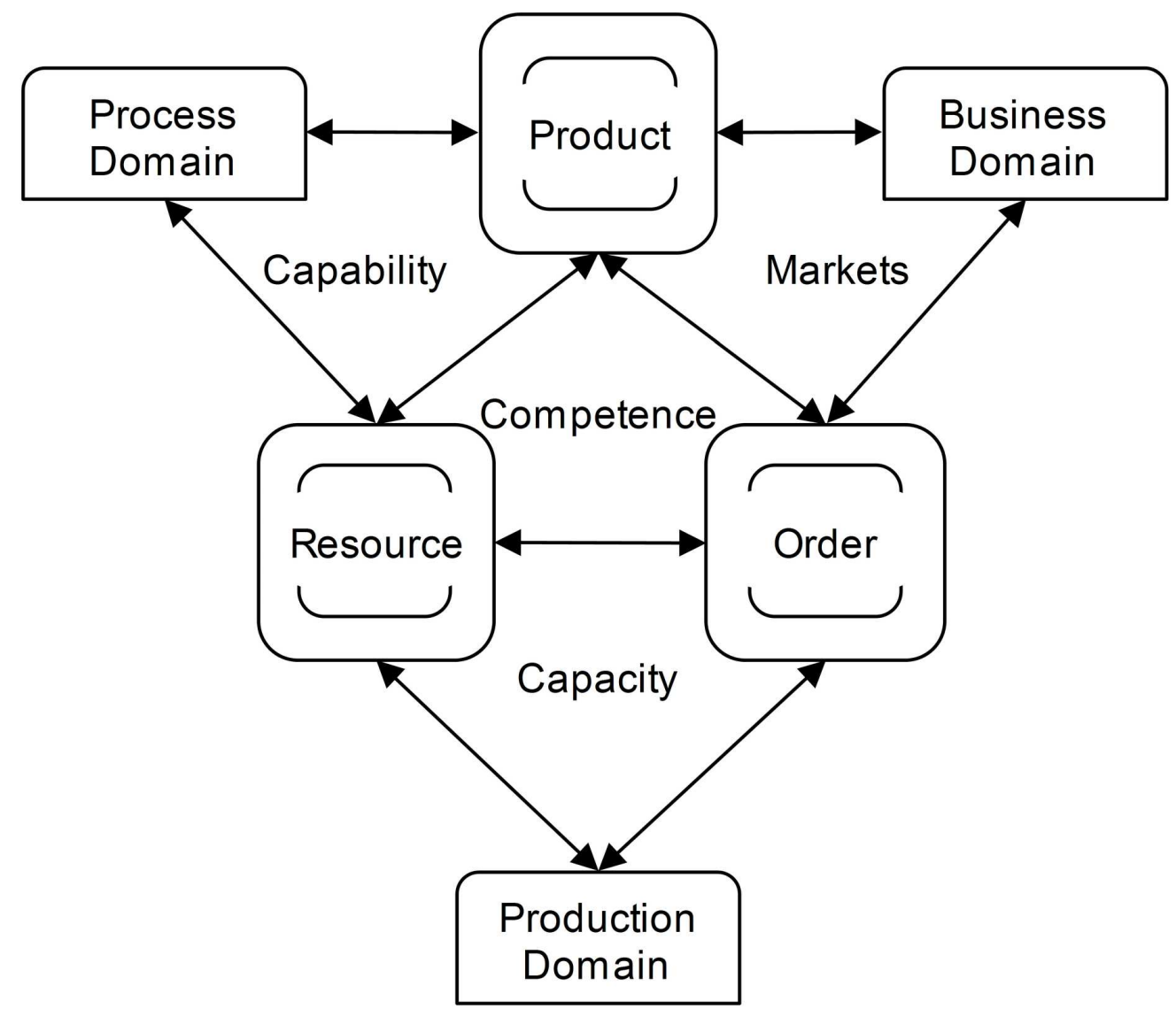

$78 \times 67 \mathrm{~mm}(600 \times 600 \mathrm{DPI})$ 


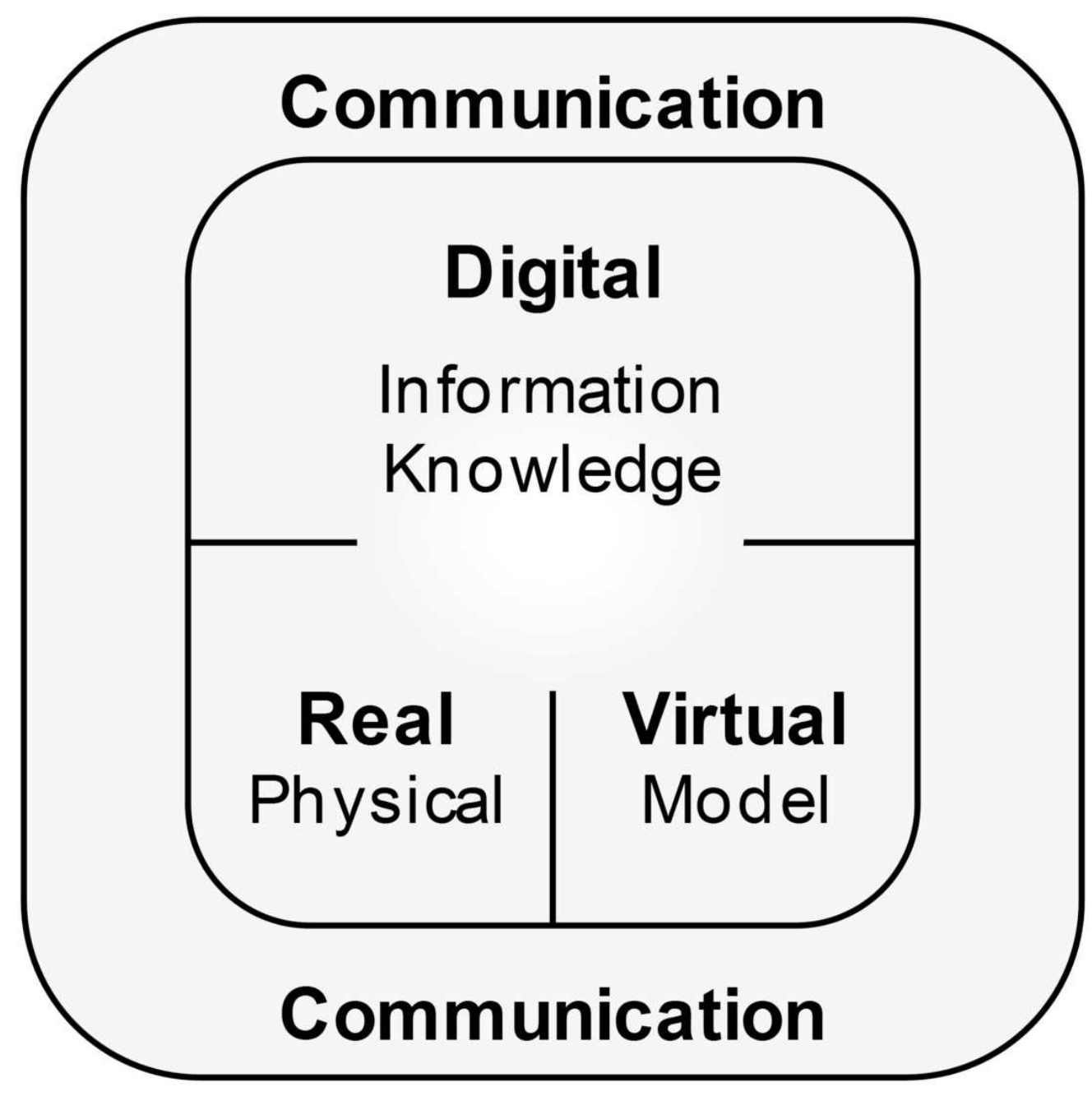

$46 \times 46 \mathrm{~mm}(600 \times 600 \mathrm{DPI})$ 


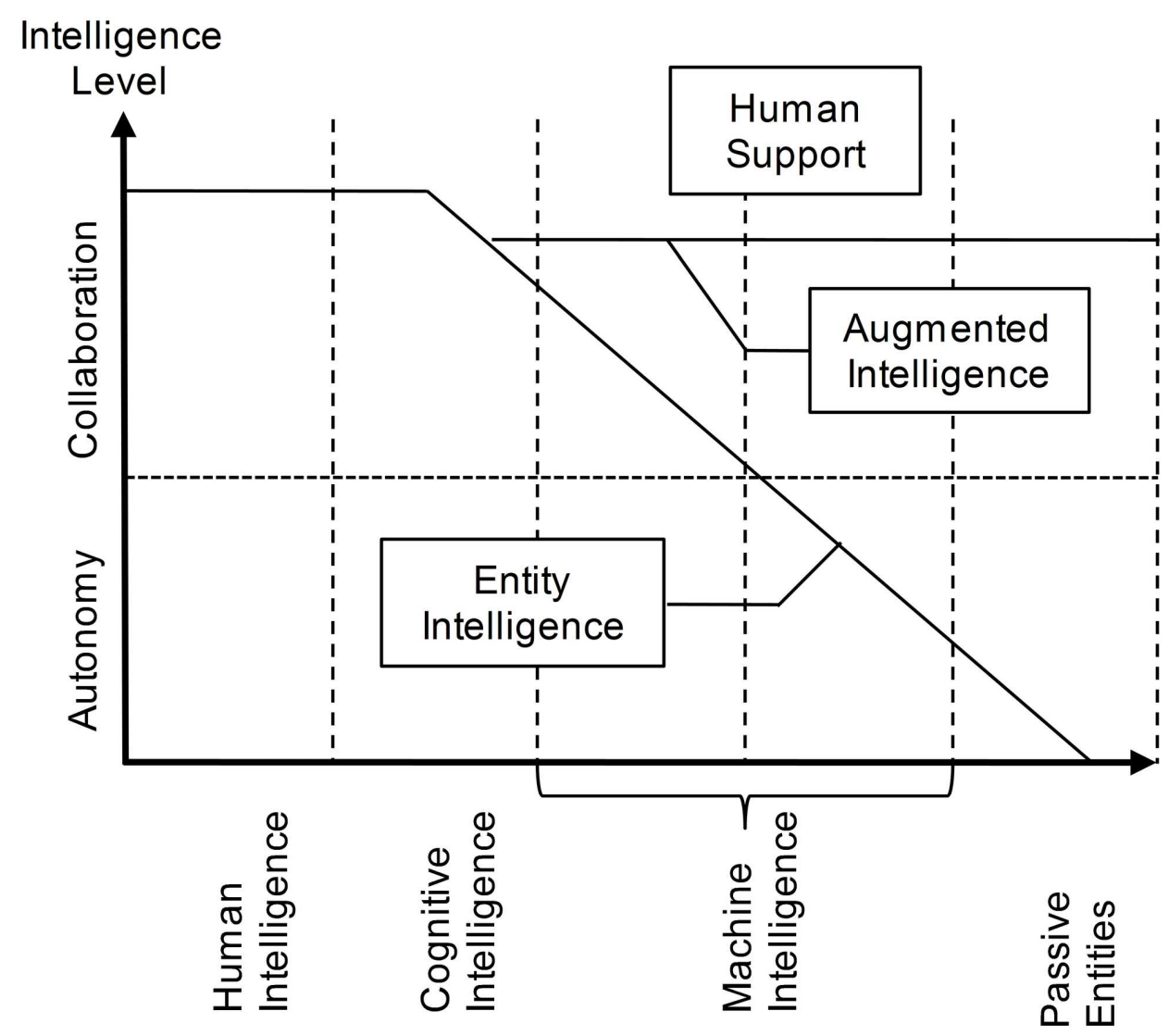

$87 \times 77 \mathrm{~mm}(600 \times 600 \mathrm{DPI})$ 


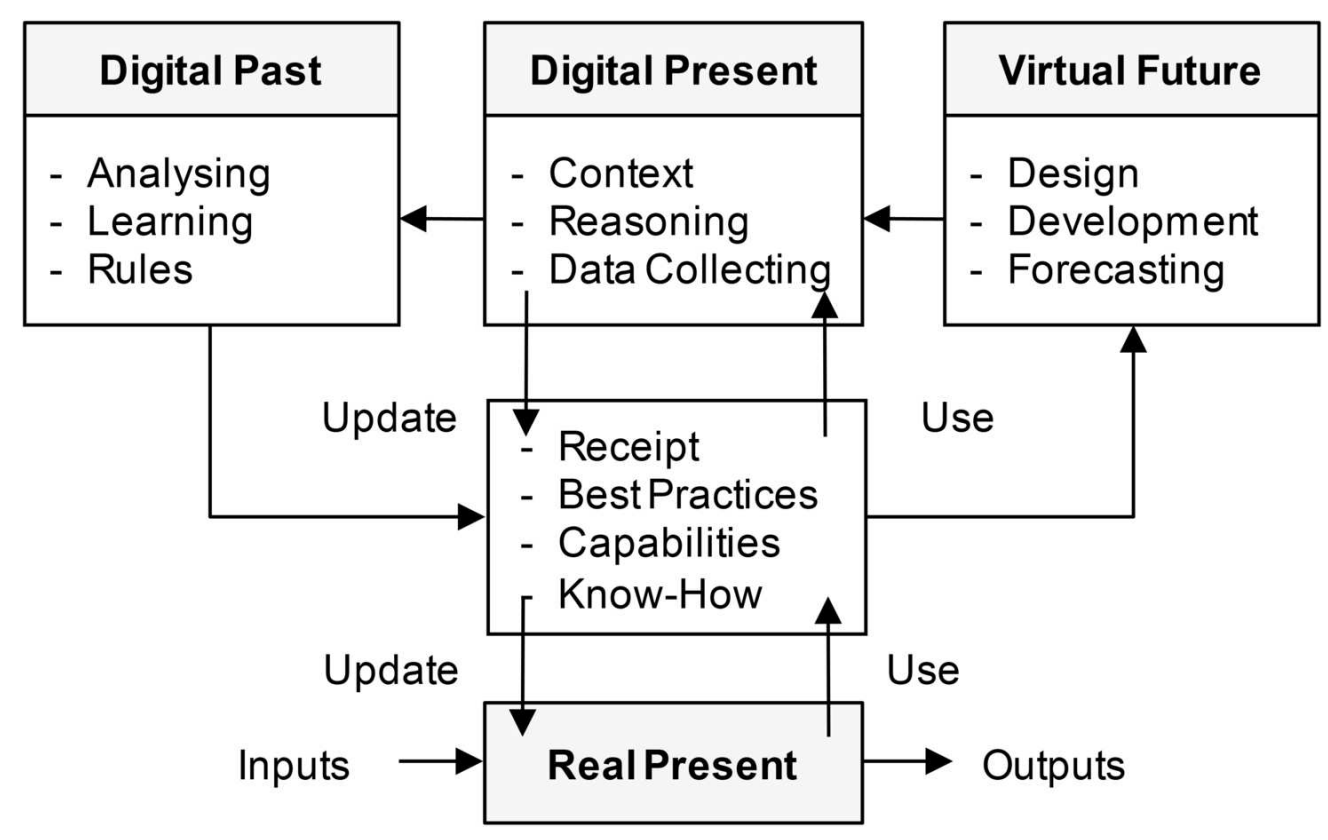

$62 \times 38 \mathrm{~mm}(600 \times 600 \mathrm{DPI})$ 


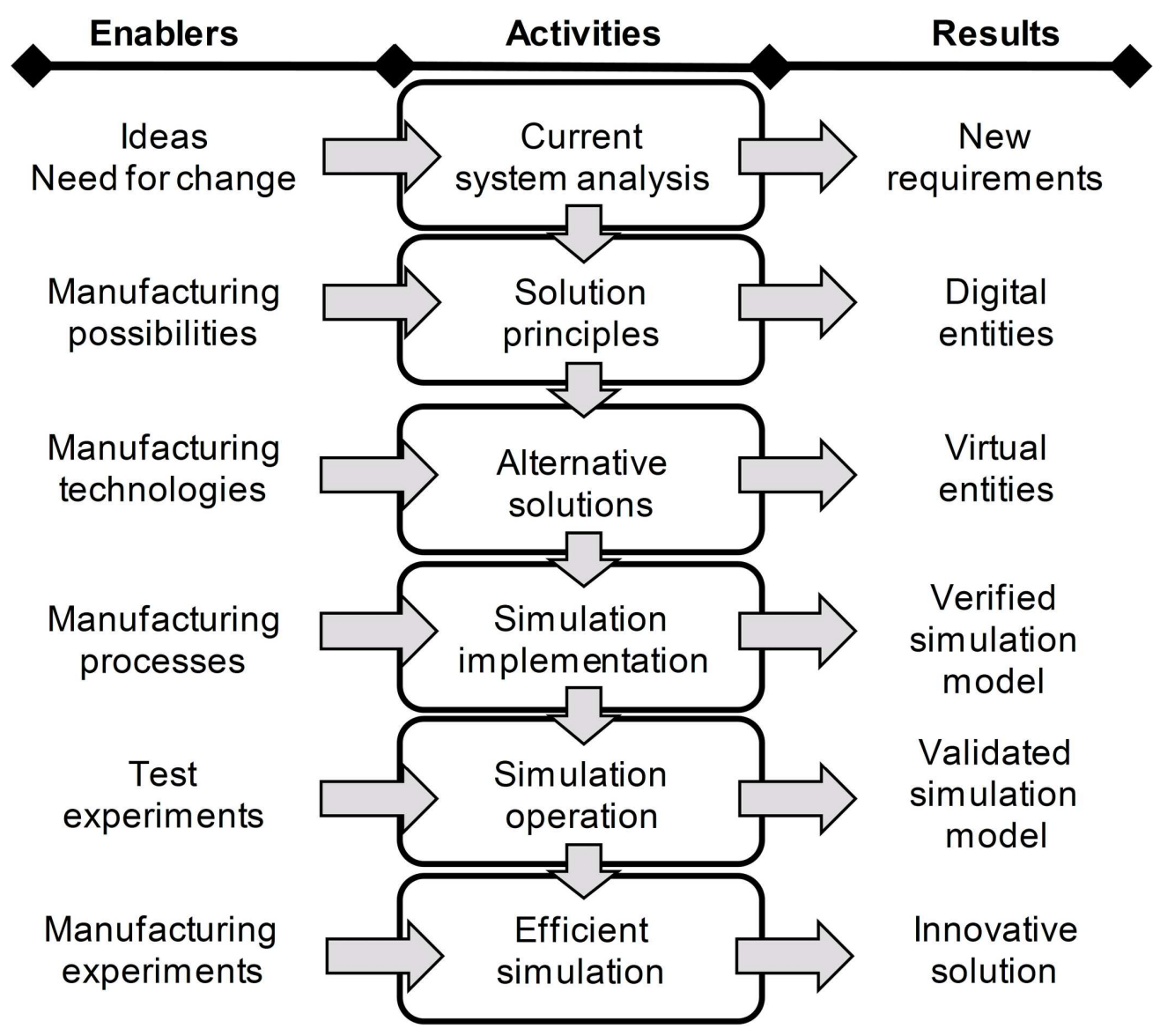

$90 \times 81 \mathrm{~mm}(600 \times 600 \mathrm{DPI})$ 

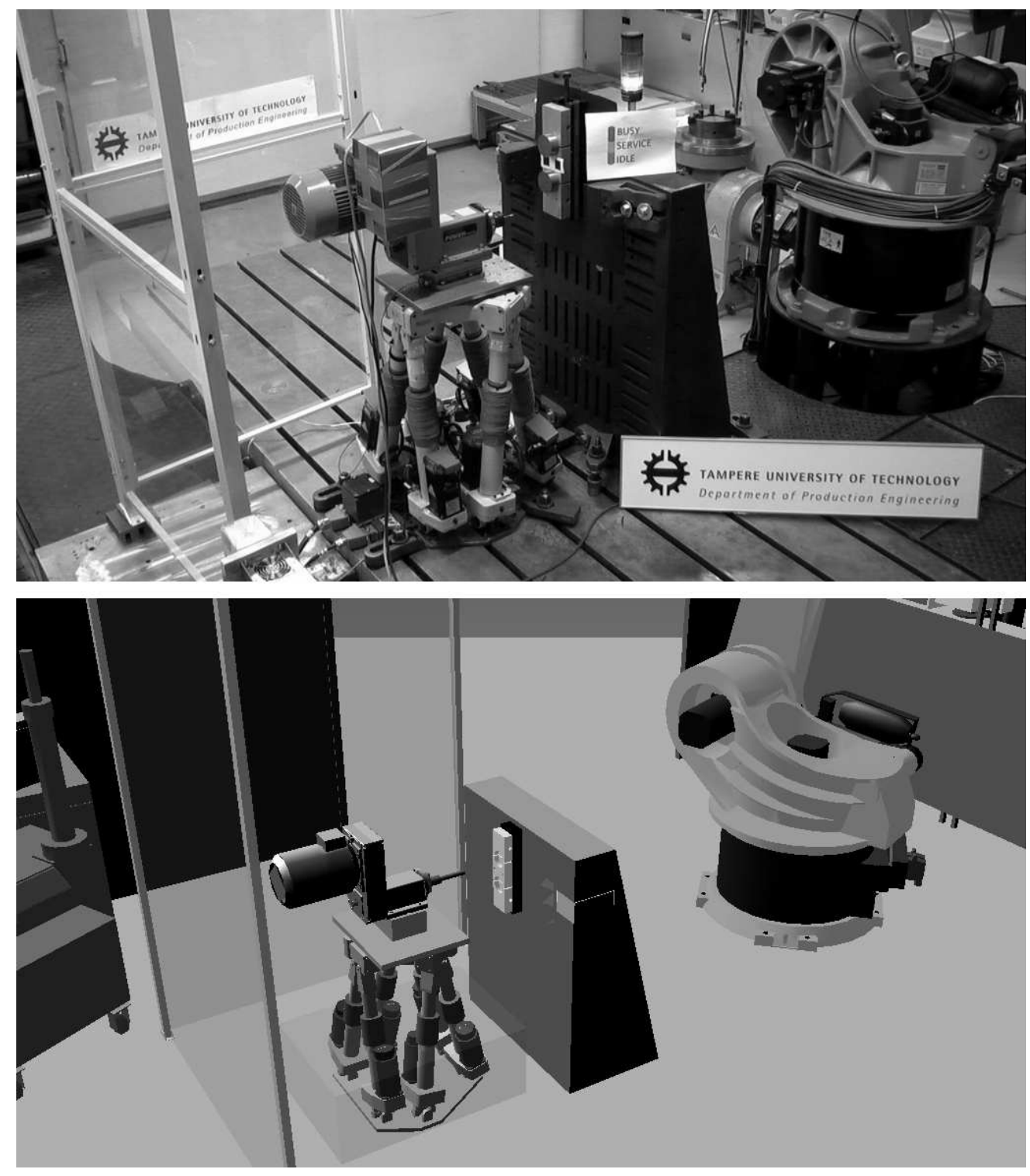

$87 \times 99 \mathrm{~mm}(300 \times 300$ DPI $)$ 


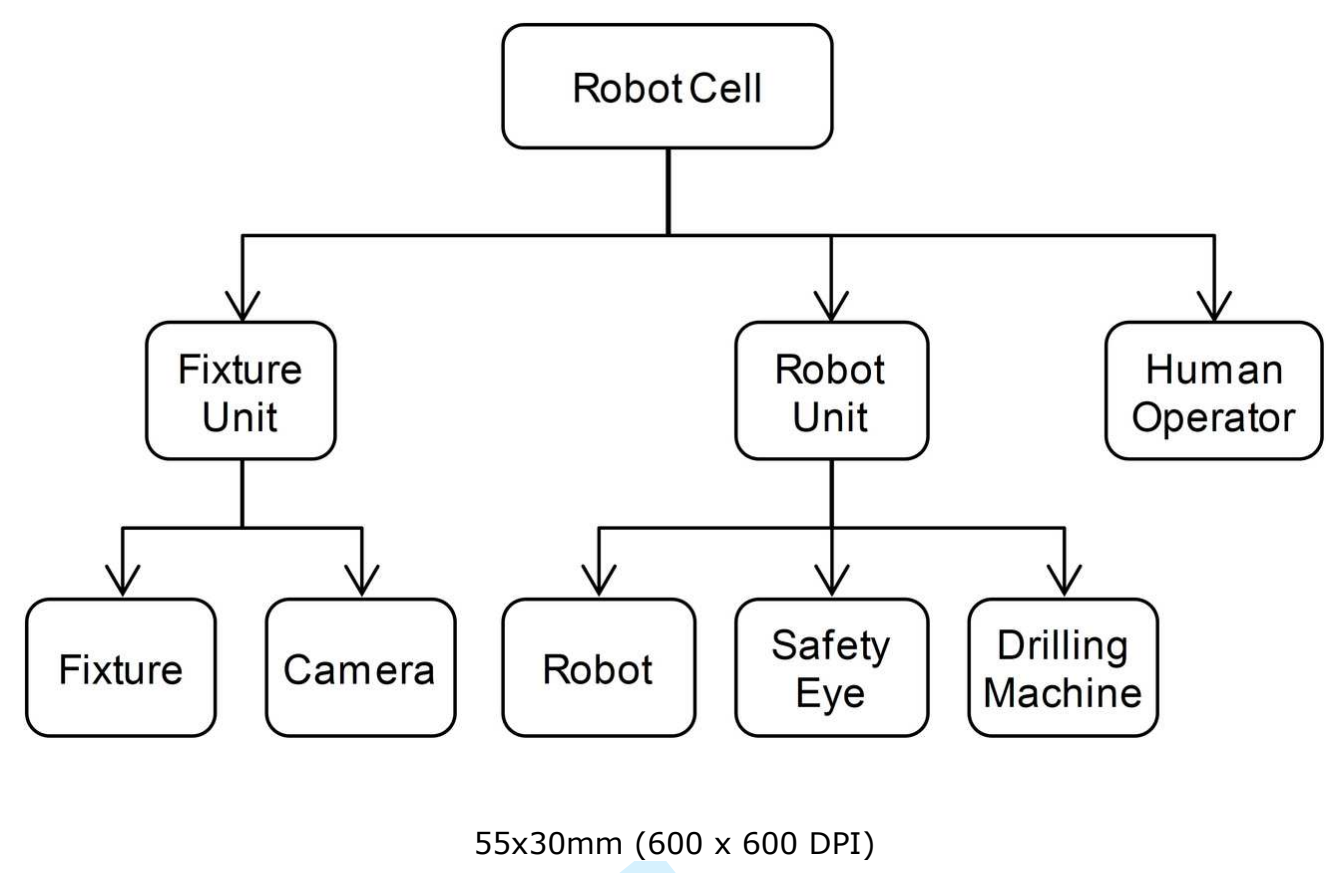




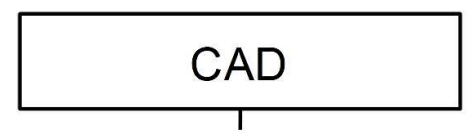

Feature
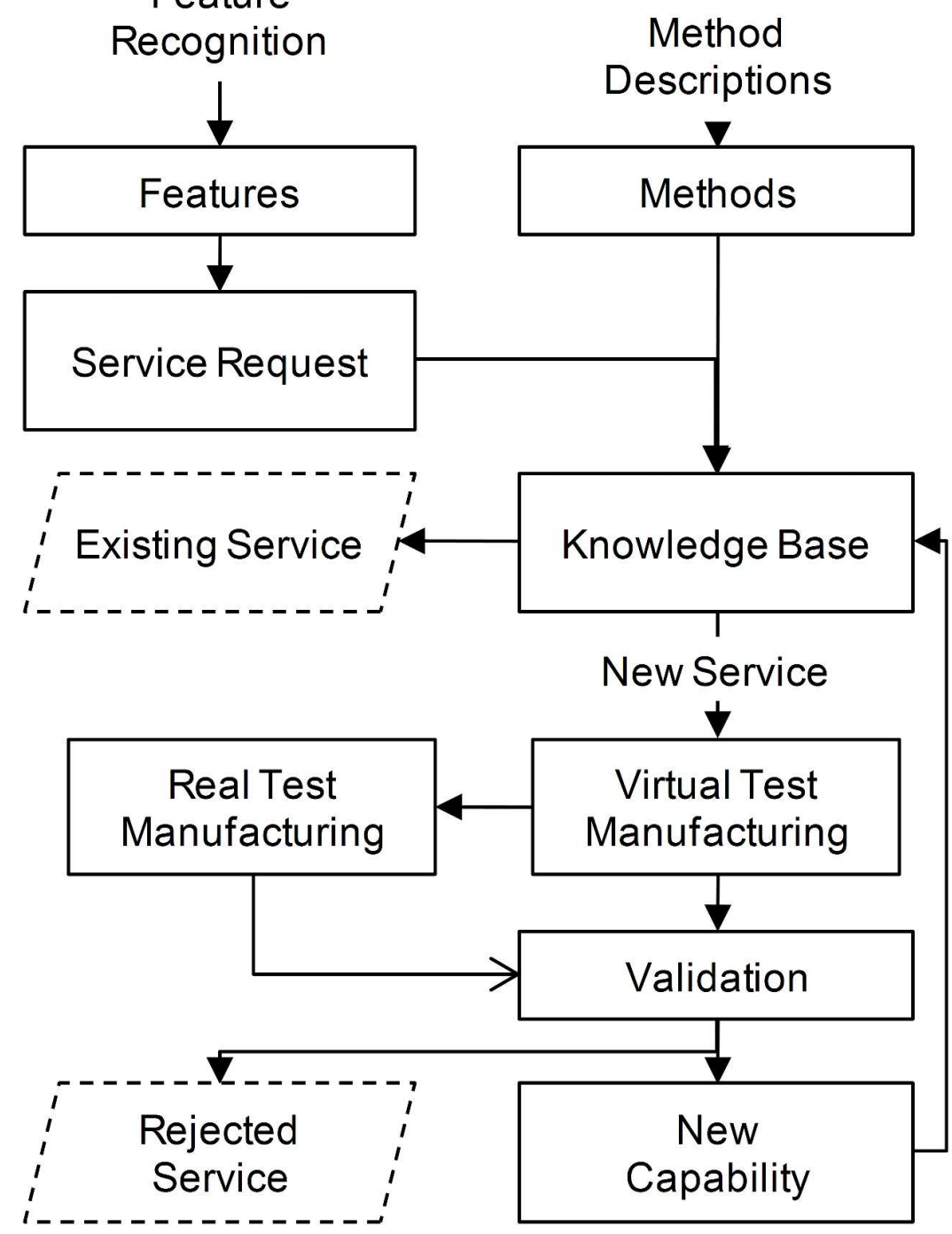

$108 \times 161 \mathrm{~mm}(600 \times 600 \mathrm{DPI})$ 


\section{Dear Reviewers and Editors}

First I like to thank you for the really valuable comments about my manuscript.

The manuscript has been revised based on the comments. I have copied the parts of the review results that have comments and suggestions, to this response. My answers to the issues are below the individual comments as bulleted lists.

Best Regards,

Mr. Hasse Nylund

\section{Reviewer: 1}

1.) Though simulations are said to be one major part of the EDMS, this aspects is rarely discussed. Which simulation systems do you use?

- Paragraphs are added into the end of Chapter 3.2.1. explaining generally which types of simulation systems are used.

- Names of used simulation software are mentioned in the end of Chapter 6.1.

Which types of models are necessary for providing the required information for augmented intelligence?

- $\quad$ This is addressed in the end of Chapter 4.1.

2.) According to the paper, some components have information about motions and behavior. In which formats are these aspects specified (data model, model hierarchy, etc.)?

- It is a theoretical example that doesn't go that deep into the details. I have added a short explanation to the end of a paragraph in the Chapter 5.2. after the Figure 5.

3.) Digital models entail engineering costs. Which approach is applied for your facilities? What about re-use of model components?

- If I understood correctly, this is about the Chapter 5.2. Process from ideas to solutions. I added a paragraph to the end of that Chapter explaining those issues shortly.

4.) Which kind of services does the EDMS provide (classification of different service types, examples)?

- This is addressed shortly at the end of the first paragraph in Chapter 4.2. The explanation is in very general and theoretical level. The details of the services belong to the future work of the environment, discussed in Chapter 6.6. 
The given taxonomy of the resource entities in the test facility is not very comprehensive because it is restricted to the test facility. For extending the scope, the authors could discuss a general form of their taxonomy followed by the example mentioned above.

- The taxonomy is presented in Chapter 2.2.1. Fractal self-similarity, even though the term taxonomy wasn't mentioned in the text. I added a paragraph into the end of Chapter 2.2.1 to discuss about taxonomy more generally than in the example in Chapter 6.1.

\section{Reviewer: 2}

Page 5. Revisit and distinguish the definitions of virtual and digital models or parts. Virtual parts are digital descriptive models and thus carry information about the real part.

- I have clarified this issue in the last paragraph of Chapter of 2.2., before Chapter 2.2.1.

Page 8 Capability falls also in the production domain, according to the definition given to production.

- I have fine tuned the definitions in Chapter 2.1. to explain why capability is in the process domain.

Fig 1. domain definitions as extensions of the PROSA needs reformulations and corrections, since each domain described has a direct relation to ALL three holons of PROS Architecture. For instance the process domain has a great deal to do with the order holon since selection of process for a given product feature is dependent on amount or shear volume of the product.

- I have edited the descriptions of the domains in Chapter 2.1, and hopefully it now explains why (in my opinion) the process domain is not directly connected to orders.

Fig 2. the verified and validated simulation models come earlier than any experimental analysis or implementations. Redo the picture or remove it at all.

- I have made some changes in the picture that it more clearly presents a simulation example (e.g. solution implementation $->$ simulation implementation). I have also added an explanation into the start of Chapter 5.2. that describes the process being a simulation example of factories or manufacturing systems where DES software is used.

\section{Editor Comments}

2. Please have your paper proof read by a native English Speaker or a person more familiar with the English language.

- The language has been checked by an official language checking service 
3. Please update your references to IJCIM format as they should be alphabetical not numbered. Also please check the journal website http://www.informaworld.com/smpp/title $\sim$ content=t713804665 db=all for IJCIM appropriate references as well.

- The references are modified 